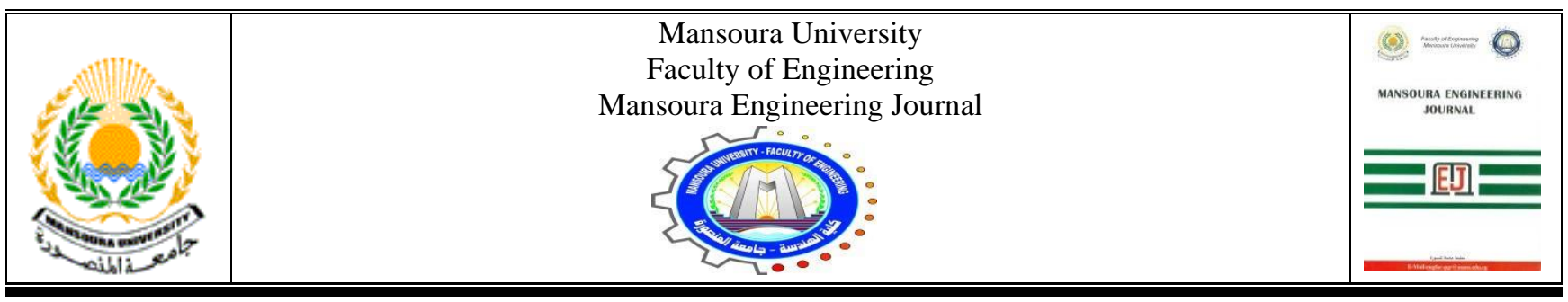

\title{
An Approach of Load Management and Cost Saving for Industrial Production Line Using Particle Swarm Optimization
}

\author{
Esraa M.Abd Elsadek, Hamdy A. Ashour, Ragi A. Hamdy, and Mohamed Moustafa M. Sedky
}

$\begin{array}{lr}\text { KEYWORDS: } & \\ \text { Particle } & \text { Swarm } \\ \text { Optimization } & \text { (PSO), } \\ \text { Cost Saving, Industrial } & \text { Production } \\ \text { Demand } & \text { Line, } \\ \text { management (DSM) }\end{array}$

Received: (31 August, 2020) - Revised: (26 October, 2020) - Accepted: (21 November, 2020)

Esraa M.Abd Elsadek is a Teaching Assistant in Dept. of Mechatronics, Alexandria Higher Institute of Engineering \& Technology, (AIET), she received her B.Sc. in 2014, (AIET), and her M.Sc in 2020, Alexandria University, Egypt, her research interests in control, power, Energy saving, Electro-pneumatic system.Engesraa560@gmail.com.

Hamdy Ahmed Abd El-Khalek Ashour. Full Professor since 2009 in Arab Academy for Science \& Technology, Department of Electrical and Control Engineering, Alexandria, Egypt. B.Sc. from Alexandria University, Egypt, 1992. M.Sc. from Alexandria University, Egypt, 1996. Ph.D. from Heriot-Watt University, Edinburgh, United Kingdom, 1999. Main areas of interest are Electrical Machines, Variable Speed Drives, Power Electronics Applications, Industrial Automation Systems, Renewable Energy and Energy Management Systems. Hamdy135@gmail.com.
Ragi A. Hamdy (Senior Member, IEEE) is Professor in the Department of Electrical Engineering, Faculty of Engineering, Alexandria University, he received the B.Sc. and M.Sc. degrees from Alexandria University, Alexandria, Egypt, in 1991 and 1994, respectively, and the Ph.D. degree from Heriot-Watt University, U.K., in 1999, his current research interests include electric machines, electric drives, and power electronics.rhamy@alexu.edu.eg.

* Corresponding author: Mohamed Moustafa M. Sedky is a lecturer in the Department of Electrical Engineering, Faculty of Engineering, Alexandria University, he received the B.Sc. and M.Sc. degrees from Alexandria University, Alexandria, Egypt, in 1994 and 1999, respectively, and the Ph.D. degree from Heriot-Watt University, U.K in 2004, , his current research interests include electric machines, electric drives, power, and power electronics. Mohamed.sedky@alexu.edu.eg. 


\section{INTRODUCTION}

$\mathrm{D}$ EMAND Side Management (DSM) is the most effective system for increasing the efficiency and saving energy for both utility and consumer. Demandside management (DSM) in the smart grid (SG) is considered as an effective solution to bridge the gap between demand and supply. DSM is performed through residential load-scheduling with the help of an energy management controller [1]. DSM concern could be divided into two main sections: load scheduling of factories and optimization techniques. A case study in a big cement factory in China used the demand side management to minimize the cost by solving the optimization problem [2]. Demand side management has studied the implementation of different industrial case studies, such as the mechanical pulp production process of paper mill site [3]. Particle Swarm Optimization (PSO) is used in Demand Side Management (DSM) to solve load shifting mathematical optimization form [4]. The results proved that using optimization techniques reduced peak load, cost and improving load factor. Using CVX in Load shaping techniques will be formulated as constrained optimization problems for direct load control purposes $[5,6]$. Most of the previous researches focused on decreasing peak demand cost and capital cost [7]. A crucial problem is found because of the big running cost as additional working hours are needed. DSM is a set of flexible programs, which allows customers to shift their own demand for electricity and reduce their energy consumption overall [8]. DSM has three important ends: customer, utility and society. The customer seeks two very important factors: decreasing the electrical bill and increasing the system efficiency [9]. Utility needs to reduce overall system energy, selling in peak hours, the pollution and emission. Where load management programs are valley filling, peak clipping, load shifting, flexible reliability, strategic load growth and strategic load conservation [10]. A Novel Approach by using Particle Swarm Optimization (PSO) algorithm is applied to the non-linear congestion management problem-based IEEE 30 bus [11], where the losses have

been minimized and maximizing load ability. Particle Swarm Optimization is proposed by Kennedy and Eberhart in 1995. The basic idea came from mimicking the social behavior of birds. This technique demonstrates that it is greatly successful in resolving a broad range of complicated optimization problems.

\section{Problem formulation}

Description of the factory line production under study is discused in this seciton. Granite factories consist of main eight sections, in this paper one section is studied. The main steps in producing a segment of granite are: cutting and polishing of each piece. The energy consumption for this section was studied, such as the number of equipment, production capacity, sequence and operation schedule. Table I shows the power consumption of each machine.
TABLE I

POWER CONSUMPTION IN MACHINES

\begin{tabular}{c||c} 
Type of Machine & Power Consumption $(\mathbf{k W})$ \\
\hline \hline Cutting machine & 29.4 \\
\hline Polishing machine & 3.675 \\
\hline Compressor & 7.35 \\
\hline Lighting & 3
\end{tabular}

The capacity of each factory is represented by number of machines, productivity target and the operational hours. Thase are very important data for the loading profile. A sector of this factory can be presented resolved and then applied to all factories if needed. The capacity of the stuided factory sector is summerised in Table II, this data will be used to calculate the power consumption. The sequence of operation of this factory is as follow. Cutting the big single granite stone into sixteen pieces which take up to five hours to be completed, then polishing granite slabs for half an hour for one piece. This should be taken into consideration while controlling the load profile of the factory.

TABLE II

CAPACITY OF GRANITE PRODUCTION FACTORY

\begin{tabular}{c||c} 
Capacity & Section of factory \\
\hline \hline Number of granite blocks & 6 \\
\hline Total piece production per day & 96 \\
\hline Number of cutting machines & 4 \\
\hline Number of polishing machines & 4 \\
\hline Operational time of cutting machines per day & 7.5 \\
\hline $\begin{array}{c}\text { Operational time of polishing machines per } \\
\text { day }\end{array}$ & 12
\end{tabular}

\section{MATHEMATICAL DSM WITH RESHAPING OF FACTORY POWER LOAD CURVE}

DSM with reshaping of factory power load curve could be studied under two different technqies. Which are; load shfiting techniue and optimization technique.

\section{A. Load shifting technique}

The proposed load management is applied based on the load shifting technique, which shifts the load from on-peak to offpeak hours. This rescheduling of load have to be done without affecting the total production target. The objective of this case study is to reduce the peak demand of this sector, which directly affects the cost. Load shifting also increases the load factor which affects the factory bill and the stability of utility. Fig. 1 shows the load profile of the granite factory before applying the proposed load management technique. 


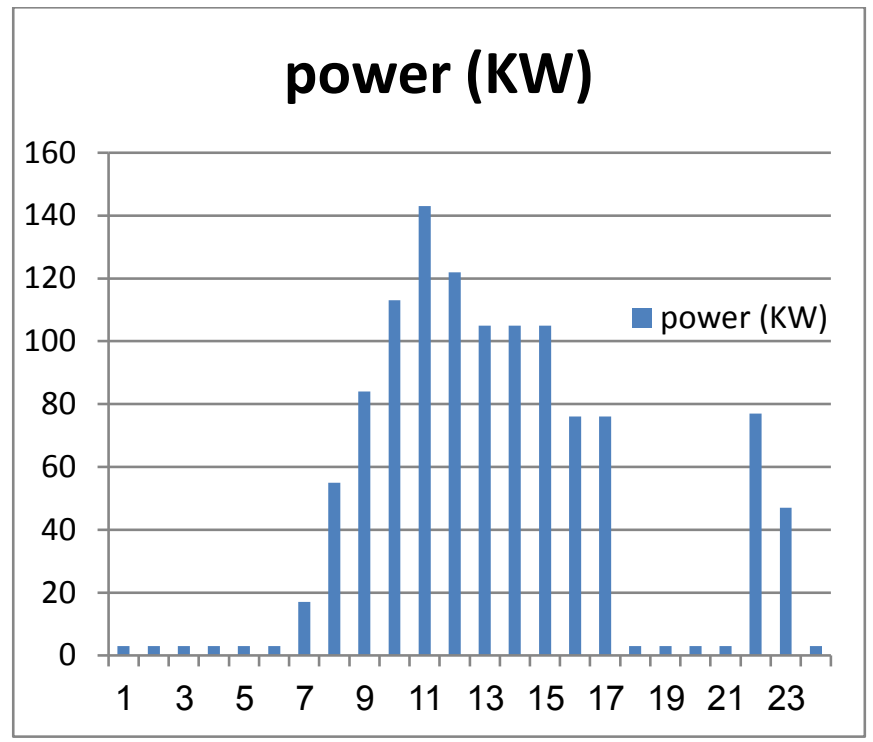

Fig.1 Existing Load Profile of One Section of the Under-Study Factory[7]

The objective function is formulated to minimize the total running cost and improve the load curve of the industrial plant factory. The equation form is divided into three sections as follows:

$$
\begin{gathered}
\min C_{T}=\left[\sum_{i=1}^{N} \sum_{j=1}^{24} P_{(i, j)} \times t_{(j)} \times C E_{(i, j)}\right]+[p(v a l) \times \\
C D]+\left[\sum_{i=1}^{N} \sum_{j=1}^{24} W h_{(j)} \times N W \times C W_{(i, j)}\right]
\end{gathered}
$$

Where section one is the total cost of the consumed power, section two is the total cost of peak demand power, and section three is the total workers ' cost.

According to constraints:

$\sum_{i=1}^{N} \sum_{j=1}^{j} P_{\text {new }(i, j)} * t_{(j)}=\sum_{i=1}^{N} \sum_{j=1}^{j} P_{\text {old }(i, j)} * t_{(j)}$

$p_{\text {new }(i, j)}=p(\mathrm{val})$ limitation the maximum power $(\mathrm{KW})$

$p_{\text {new }(i)} \geq p_{\text {old }(i)}$ during off-peak

$p_{\text {new }(i)} \leq p_{\text {old }(i)}$ during on-peak

Where $P_{\min }=3 \mathrm{KW}$, and $\mathrm{P}_{\max }=143 \mathrm{KW}$, as shown in Fig. 1

The objective function (1) aims to decrease the factory cost by applying load shaping techniques, in addition to improve the load factor, also the average and maximum power are aimed to be approximately equal. Constraint (2) ensures that energy consumption after applying a load shifting method is equal to the total energy consumption before load shifting. In peak load duration, the new power of this region cannot exceed $P_{(v a l)}$ as in constraint (3). $P_{(v a l)}$ is estimated using simulation to reduce the power at peak hour consumption. Constraints (4) and (5) ensure that the new power demand is reduced in peak hours and increased during off-peak hours. Constraints of $\mathrm{P}_{\min }$ and $\mathrm{P}_{\max }$ are the minimum and maximum limitations of new power.

\section{B. Optimization technique}

The optimization technique is needed to reshape the load curve. The optimal load profile is the most saving in capital cost, running cost and improving load factor, system reliability and performance. This section handles two types of optimization techniques that are used and comparing the results in different cases. The optimization tools, which are introduced in this section are Particle Swarm Optimization, PSO, and CVX which is a simple solver model for constructing and using DSM.

\section{Convex optimization software (CVX)}

CVX is a solver model for constructing and disciplined convex programs (DCPs). CVX supports a lot of programs such as linear, nonlinear, and quadratic. CVX is implemented in MATLAB $\AA$, as m-file into an optimization modelling language. Model specifications are constructed using the operations and functions of MATLAB ${ }^{\circ}$. This solver uses those constructions to the simplicity of the formulated problems. It is simple to perform the calculations that needed to form optimization problems, give the solution as a result of the problem by varying the constraints. CVX can be used for a larger system that uses convex optimization, such as a branching method, or an engineering workspaces design [12]. The flow chart of CVX technique is shown in Fig.2, where the technique is ended at the given constraints.

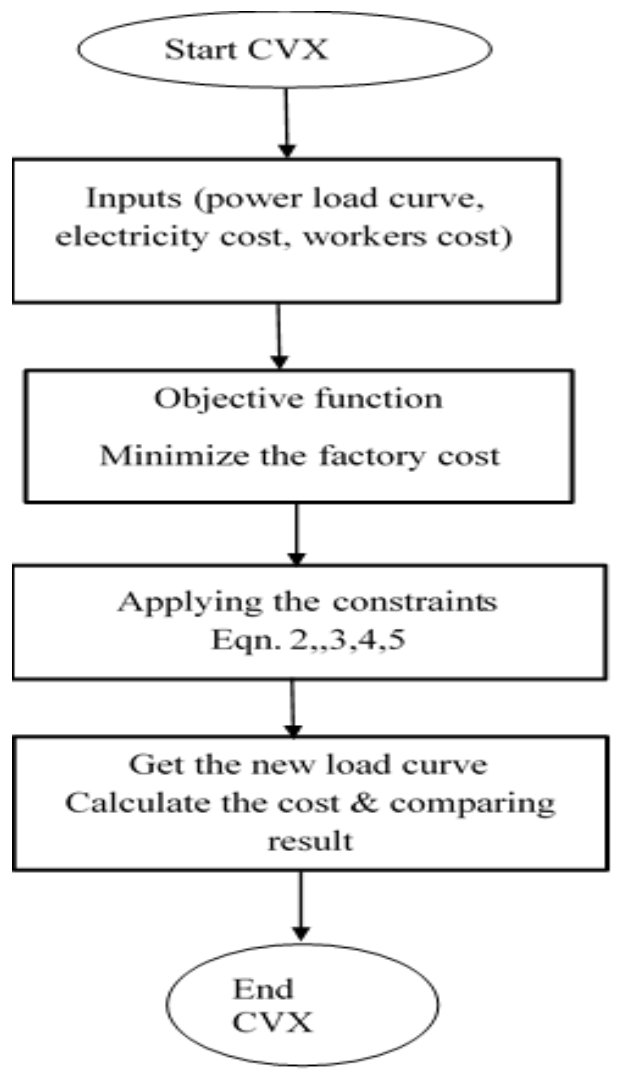

Fig. 2 CVX flow chart.

\section{Particle swarm optimization technique}

PSO technique initially evaluates a population of solution, which is called a swarm. This swarm consists of particles, each particle presents the iteration solution, till finding the optimal value related to the objective function[13]. To find the optimal solution, these particles search in space and update their velocities. Through iterations position and velocity are updating to find local best and then global best according to (6) and (7). 
PSO algorithm consists of ' $n$ ' particles. Each particle's case is changing according to:

- Best optimization of the position of the particle.

- Best optimization of the position of the swarm

$$
\begin{gathered}
\mathrm{v}_{\mathrm{i}}^{\mathrm{k}+1}=\mathrm{w} \mathrm{v}_{\mathrm{i}}^{\mathrm{k}}+\mathrm{c}_{1} \operatorname{rand}_{1}\left(\text { pbest }_{\mathrm{i}}-\mathrm{s}_{\mathrm{i}}^{\mathrm{k}}\right) \\
\quad+\mathrm{c}_{2} \operatorname{rand}_{2}\left({\text { gbest } \left.-\mathrm{s}_{\mathrm{i}}^{\mathrm{k}}\right)}\right) \\
s_{i}^{k+1}=s_{i}^{k}+v_{i}^{k+1}
\end{gathered}
$$

The best performance in getting global best value is one of the main features of the PSO algorithm. PSO technique eliminates the sinking in a local minimum value. To avoid this, the value of the weighting gain must be calculated. There are many techniques used for getting the inertia weight as adaptive inertia weight, chaotic inertia weight, and linear decreasing method. The linear decreasing technique gives a good presentation for the system, which needs to achieve a global minimum value. The inertia weight is given in equation (8).

$$
w=w_{\max }-\frac{w_{\max }-w_{\min }}{\text { Iter }_{\max }} * \text { Iter }
$$

The concept of modification of a searching point of PSO is computing the new particle $\left(s_{i}\right)$, then evaluating its new location. If fitness $\left(s_{i}\right)$ is better than fitness (pbest), then pbest $=s_{i}$ in the end of iteration gbest $=$ pbest [14]. Where the flowchart illustrates the program sequence is given in Fig 3.

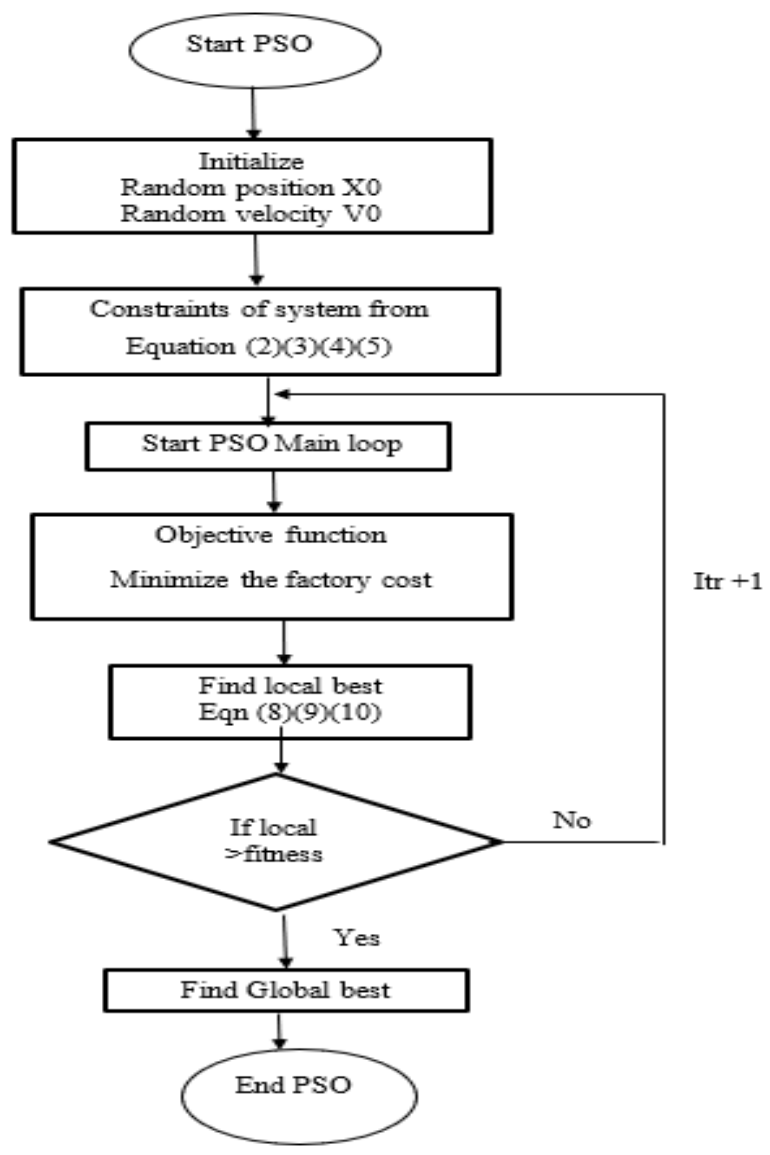

Fig. 3 PSO Flow Chart.

\section{RESULTS AND DISCUSSIONS}

Demand Side Management (DSM) with reshaping of power load curve will be studied under two parts. Part A is the effect of limitation on the cost function, which will be analysed individually. Part $\mathrm{B}$, is the effect of conditioned limitation on the cost function which will be analysed by PSO

\section{A. Effect of Changing Limitations}

Limitation will be studied individually, where Eqn. (1) has three main parameters: the cost of peak demand power, the workers cost and the electricity cost.

The individual effect of each parameter will be first studied in the following section, to analyse the effect before the utilization of proposed optimization techniques.

\section{Maximum power}

The main objective of the load shifting technique is to decrease the peak demand power, which affects the total cost. In this section the effect of changing the maximum power is studied with only one constraint that keeps the total consumed power constant. For each load profile of Fig. 4, the total cost has been calculated based on different values of maximum power $(90,70,55 \mathrm{KW})$. And the result has been listed in Table III.

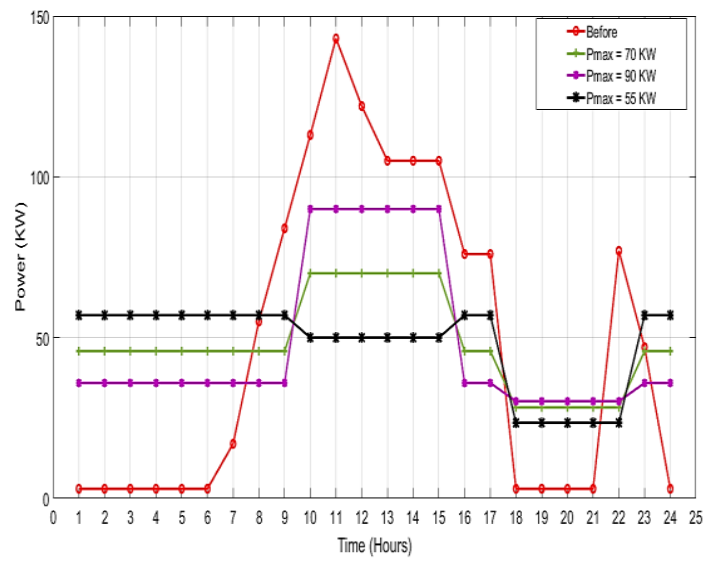

Fig. 4 Effect of changing the maximum power demand on the load curve shape.

TABLE III

THE TOTAL COST EFFECT OF MAXMIMUM POWER

\begin{tabular}{c||c} 
Pmax value & $\begin{array}{c}\text { The total running cost } \\
\text { L.E/month }\end{array}$ \\
\hline \hline After set $p m a x=90$ & 81434 \\
\hline After set $p m a x=70$ & 80176 \\
\hline After set $p m a x=55$ & 79132
\end{tabular}

From table III, it can be noticed that the cost in three cases has increased after load shifting and this arises from increasing the total working hours particularly during peak hours of electricity cost. By comparing the three cases of load shifting together, it can be seen that Pmax $=55$ provided the smallest demand cost. The total running cost is decreased with Pmax reduction by assuming the working hours are constant. 


\section{Workers`cost}

The total workers' cost is affected by three parameters: the cost of workers per hour, the number of workers and the number of working hours. The working hours are divided into two shifts: day shift and night shift. This cost of workers is assumed to be changed from day to night shift to be $10 \mathrm{~L}$.E/hr and 12 L.E/hr respectively. The night shift could start at $6 \mathrm{pm}$ or $8 \mathrm{pm}$.

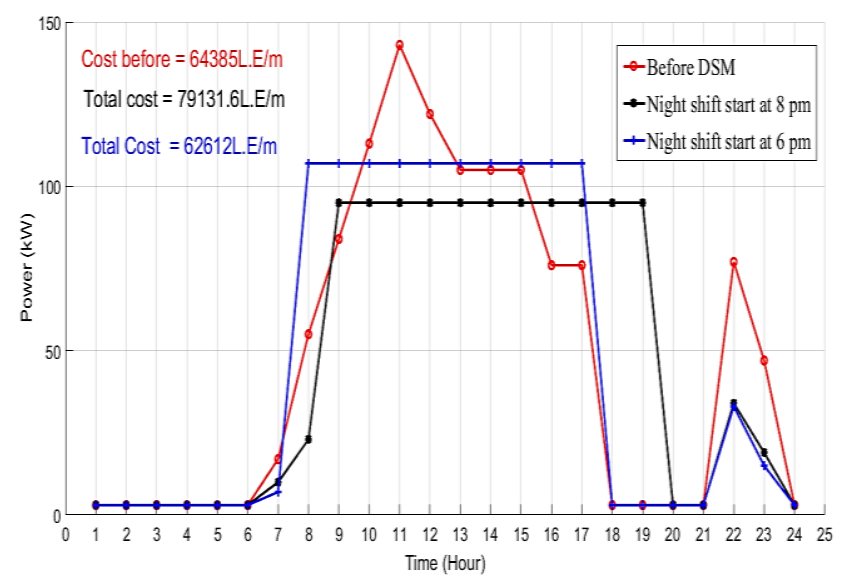

Fig .5 The new load curve after load shifting with variations of working hours.

Fig. 5 shows the different load curves for two shifts. Where night shift one is starting at $6 \mathrm{pm}$, and night shift two is staring at $8 \mathrm{pm}$. The two night shifts are ending at $7 \mathrm{am}$. It can be seen that for the shift starts at $6 \mathrm{pm}$, more saving is achieved. That is because of the working hours for day shift one is less than the working hours for day shift two. The only drawback of load curve one is that it has a higher peak demand. Table IV compares the two shifts in terms of the total running cost, peak demand, worker cost, and electricity cost.

TABLE IV

THE TOTAL RUNNING COST EFFECT OF WORKERS COST

\begin{tabular}{c||c||c} 
& $\begin{array}{c}\text { With night shift } \\
\text { start at 6 pm }\end{array}$ & $\begin{array}{c}\text { With night shift start at 8 } \\
\text { pm }\end{array}$ \\
\hline \hline $\begin{array}{c}\text { The total } \\
\text { running cost } \\
(\mathrm{L} . \mathrm{E} / \mathrm{m})\end{array}$ & 67212 & 62612 \\
\hline $\begin{array}{c}\text { Peak load } \\
(\mathrm{KW})\end{array}$ & 95 & 107 \\
\hline $\begin{array}{c}\text { Worker cost } \\
(\mathrm{L} . \mathrm{E} / \mathrm{m})\end{array}$ & 23700 & 20700 \\
\hline $\begin{array}{c}\text { Electricity } \\
\text { cost }(\mathrm{L} . \mathrm{E} / \mathrm{m})\end{array}$ & 38760 & 36562
\end{tabular}

\section{Electrical cost}

The cost of electricity is based on an Egyptian electricity company plan 2019 [15] for industrial loads, is divided into three sections: on-peak, off-peak and average, which are during the off-peak $.96 \mathrm{pt}$ and during the on-peak $1.45 \mathrm{pt}$. The peak hours start from $6 \mathrm{pm}$ to $10 \mathrm{pm}$, off peaks start from $2 \mathrm{am}$ to 7 am otherwise is the average. The result of load shifting with only electrical cost as the limitation can be shown in Fig 6 .

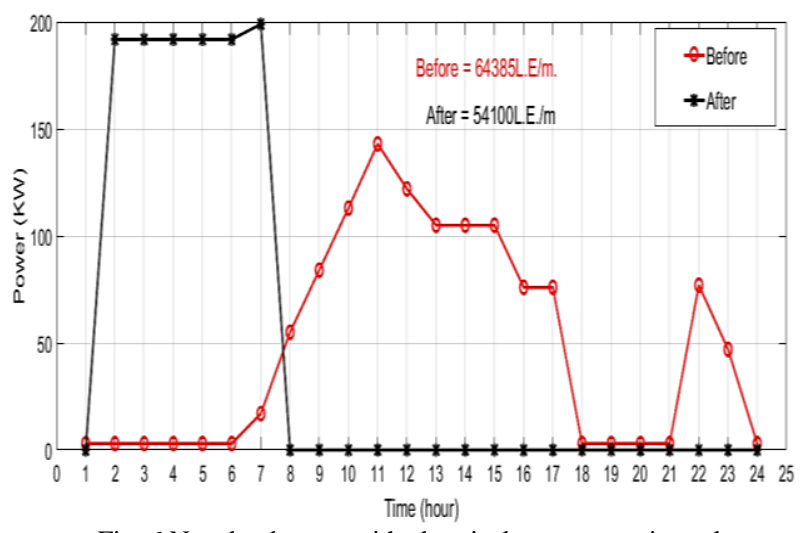

Fig. 6 New load curve with electrical cost constraint only.

From Fig. 6, the output load curve is shifted to be work only in the off-peak period, causes a high increase in maximum power. The total running cost is decreased because of decreasing the working hours, but the capital cost has dramatically increased because of increasing the peak demand as shown in Table $\mathrm{V}$.

TABLE V

COMPARING THE COST BEFORE AND AFTER LOAD SHIFTING WITH ELECTRICITY COST CONSTRAINTS

\begin{tabular}{c||c||c} 
& Before DSM & After DSM \\
\hline \hline Total Energy $($ KWh $)$ & 1158 & 1158 \\
\hline Peak power $($ KW) & 143 & 199 \\
\hline $\begin{array}{c}\text { Peak demand cost } \\
(\text { L.E/m) }\end{array}$ & 7150 & 9950 \\
\hline $\begin{array}{c}\text { Electricity cost } \\
(\text { L.E/m) }\end{array}$ & 36534 & 33351 \\
\hline $\begin{array}{c}\text { Workers cost }(\text { L.E/m) } \\
\text { Total running cost } \\
(\text { L.E/m) }\end{array}$ & 20700 & 10800 \\
\hline
\end{tabular}

From Table $\mathrm{V}$ it was found that, the new load curve running cost is less than the existing one as the working hours have reduced. On the other hand, the peak demand has increased which affects the total cost.

\section{B. Cost optimization techniques}

In this section two different optimization techniques are applied, which are CVX, and PSO.

\section{CVX with six hours shut down}

Case (1) is using CVX to shift the peak power with constant energy consumption ( 6 hours shut down), with assumptions of the input power load curve of the granite factory is entering by vector of twenty-four columns, and the cost of electricity taken from an electricity company for industrial loads as will be drawn by MATLAB $囚$. The cost of employees per hour which changes from day to night shift that differs for almost $1.2 \%$. In order to satisfy the main objective of the program to reduce the overall cost of the varying energy, there are various limitations, which are; the total consumed energy of the day should be constant, the maximum power should be reduced increasing the power during the off-peak hours, and decreasing the power 
during on-peak hours. The results is shown in Fig. 7, and Table VI shows that the peak power consumption in $\mathrm{KW}$ has decreased.

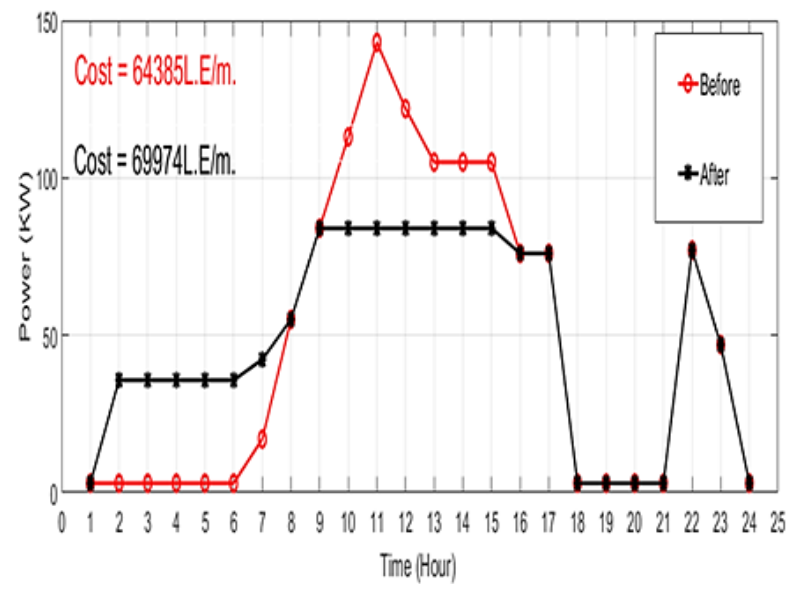

Fig. 7 Load Curve after Applying Load Shifting DSM Program on CVX without shut down period case(1).

From Fig. 7 the power load curve after applying DSM using CVX is better than the curve before DSM in terms of maximum power as it reduces demand cost. But the total cost is increased because of increasing the working hours which affect the workers' cost and lighting cost. Therefore, a shutdown period will be increased and studied in the following case study (case 2).

\section{CVX with ten hours shut down}

Case(2) is using CVX to shift peak demand with shut down period during on-peak (ten hours shut down) with the same assumptions and limitations of case (1), but the shut down period (minimum four hours) is added.

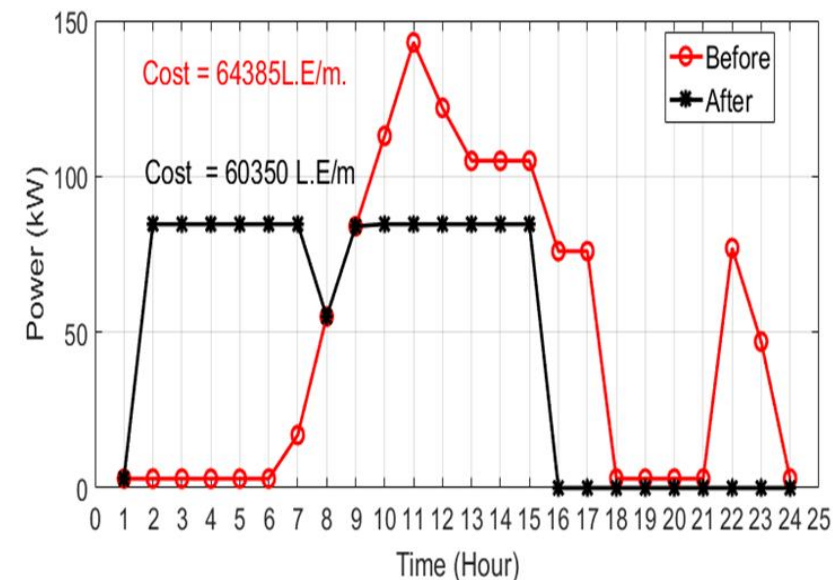

Fig. 8 Load Curve after Applying Shifting using CVX with a shutdown period case(2).Table VII The Cost Results of the factory before and after applying Case (2)

From Fig. 8, and Table VII, it can be seen that with the 10 hours shut down period, the CVX program can optimize the load shifting curve to get significant decreased in peak demand approximately $40 \%$ and a slight decrease in total running cost with reduction approximately $6.2 \%$, which the saving account about 4035 L.E per month and 48420 L.E per year.

TABLE VII

THE COST RESULTS OF THE FACTORY BEFORE AND AFTER APPLYING CASE (2)

\begin{tabular}{l||l||l}
\multicolumn{1}{c||}{ Item per } & Before DSM & $\begin{array}{l}\text { After DSM } \\
\text { Case (2) }\end{array}$ \\
\hline \hline Total energy (KWh) & 1158 & 1158 \\
\hline Peak load (KW) & 143 & 85 \\
\hline Load factor & 0.3374 & 0.5699 \\
\hline Electrical Cost (L.E/m) & 36534 & 35100 \\
\hline Demand cost (L.E/m) & 7150 & 4250 \\
\hline Working hours & 13 & 14 \\
\hline Workers cost (L.E/m) & 20700 & 21000 \\
\hline $\begin{array}{l}\text { Total running cost } \\
\text { (L.E/m) }\end{array}$ & 64385 & 60350
\end{tabular}

The results obtained from the proposal of the shut-down period are much more beneficial since the peak demand is reduced, hence the overall electricity bills are reduced. Also, the shifting of working hours to be during the off-peak period, with the shutdown ten hours periods reduced the overall workers cost. Hence the overall operation and electrical energy costs are reduced.

\section{PSO with six hours shut down}

Case(3) is using a Particle Swarm Optimization technique with shutdown period of six hours at any time during the day. In order to satisfy the main objective of the program to reduce the overall cost of the varying energy, the following limitations are given:

The total consumed energy of the day should be constant, the maximum power should be reduced, increasing the power during the off-peak hours, decreasing the power during on-peak hours, and the shutdown period is minimum of six hours.

The results are shown in Fig. 9. From Table VIII, it is found that the peak demand power is decreased, but the total cost is increased by applying the PSO.

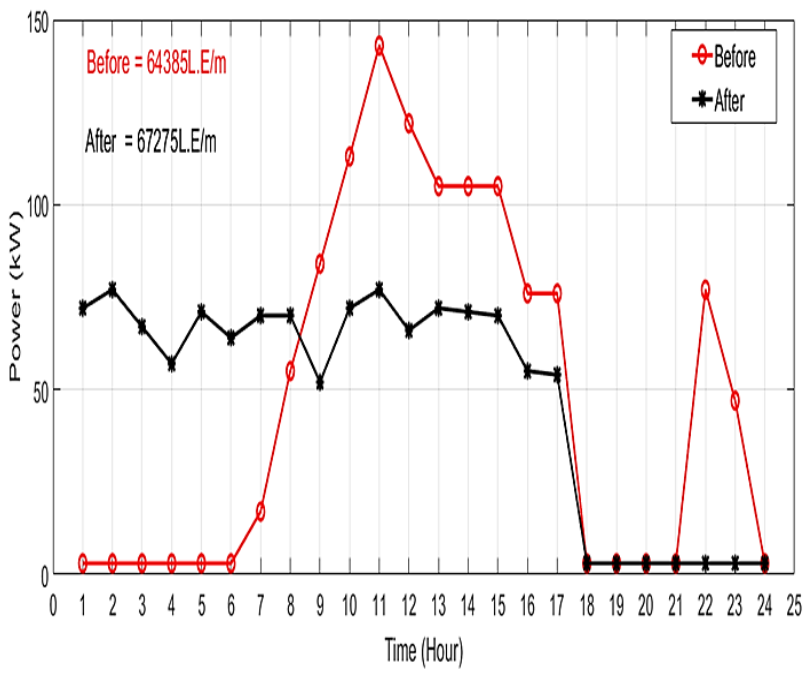

Fig. 9 Load Curve after Applying Load Shifting using PSO (Case 3). 
TABLE VIII

THE COST RESULTS OF THE FACTORY BEFORE AND AFTER

\begin{tabular}{c||c||c}
\multicolumn{1}{c||}{ APPLYING CASE (3). } \\
Item & Before DSM & $\begin{array}{c}\text { After DSM } \\
\text { Case (1) }\end{array}$ \\
\hline \hline $\begin{array}{c}\text { Total energy } \\
(\mathrm{KWh})\end{array}$ & 1158 & 1158 \\
\hline Peak load (KW) & 143 & 77 \\
\hline $\begin{array}{c}\text { Electrical Cost } \\
(\mathrm{L} . \mathrm{E} / \mathrm{m})\end{array}$ & 36534 & 35525 \\
\hline $\begin{array}{c}\text { Demand cost } \\
(\mathrm{L} . \mathrm{E} / \mathrm{m})\end{array}$ & 7150 & 3850 \\
\hline Working hours & 13 & 18 \\
\hline $\begin{array}{c}\text { Workers cost } \\
(\mathrm{L} . \mathrm{E} / \mathrm{m})\end{array}$ & 20700 & 27900 \\
\hline $\begin{array}{c}\text { Total running cost } \\
(\mathrm{L} . \mathrm{E} / \mathrm{m})\end{array}$ & 64385 & 67275
\end{tabular}

In this case, shut down period is six consecutive hours which has a significant effect on the peak demand which is decreased by approximately $46 \%$. But the running cost is increased because of the increasing working hours.

\section{PSO with ten hourse shut down}

Case(4) is using a Particle Swarm Optimization technique with shutdown period of 10 hours at any time during the day. In Case (4), it has the same assumption of case (3), while the shunt down period is increased to be ten hours. The results can be shown in Fig. 10 and Table IX. The peak demand is therefore decreased from 143 to $100 \mathrm{KW}$ which is approximately $30 \%$, and the running cost is decreased for approximately $6.6 \%$ which saves around 4259 L.E in a month and 51108 L.E in a year.In this case, shut down period is increased to be ten hours, which decreases both peak demand cost and the running cost. The disadvantage of this case may be that the power value is fluctuating.

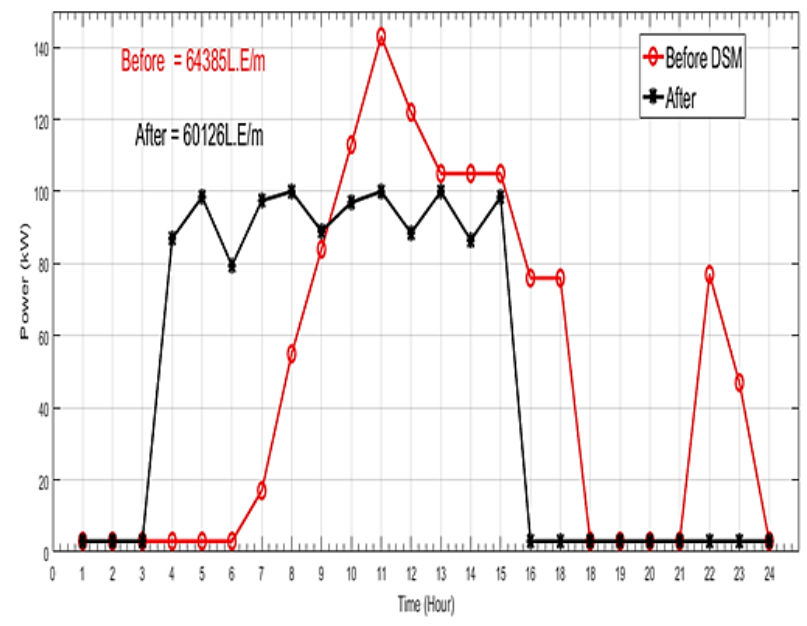

Fig.10 Load curve after applying load shifting using PSO (case4)
TABLE IX

THE COST RESULTS OF THE FACTORY BEFORE AND AFTER APPLYING PSO CASE (4)

\begin{tabular}{l||l||l} 
Item & Before DSM & $\begin{array}{l}\text { After } \\
\text { Case (4) }\end{array}$ \\
\hline \hline Total energy (KWh) & 1158 & 1158 \\
\hline Peak load (KW) & 143 & 100 \\
\hline Electrical Cost (L.E/m) & 36534 & 35626 \\
\hline Demand cost (L.E/m) & 7150 & 5000 \\
\hline Working hours & 13 & 14 \\
\hline Workers cost (L.E/m) & 20700 & 19500 \\
\hline $\begin{array}{l}\text { Total running cost } \\
\text { (L.E/m) }\end{array}$ & 64385 & 60126
\end{tabular}

\section{Conclusion}

Since the load profile of industrial loads can be reshaped to save energy and hence reduce the total cost of the factories, load shifting technique as a demand-side management (DSM) strategy has been studied to reduce the peak demand and also the total running cost. The optimization cost function has been formulated to calculate the total running cost within three main parameters: electricity cost, peak demand cost and workers cost. Two optimization techniques have been utilized and compared to find the optimal load pattern: Particle Swarm Optimization algorithm and CVX in MATLAB library. Different operating conditions and cases have been studied by changing the program constraints and parameters. The obtained results showed that the load shifting technique can reduce the peak demand while the running cost could be increased as the working hours increasing. Hence the shut-down period has been suggested and taken into consideration within the optimization program. Then the final results indicated a better reduction in total cost.

\section{NOMENCLATURE}

\begin{tabular}{|c|c|}
\hline $\boldsymbol{P}_{(i, j)}$ & is the load demand \\
\hline $\mathrm{i}$ & is the load number. \\
\hline $\mathrm{N}$ & $\begin{array}{l}\text { is the total number of factories; in this study case one } \\
\text { factory is used. }\end{array}$ \\
\hline $\mathrm{j}$ & is the total number of time intervals \\
\hline$C_{T}$ & $\begin{array}{l}\text { is the total running cost of the electrical demand and } \\
\text { energy consumption }\end{array}$ \\
\hline$C E_{(i, j)}$ & $\begin{array}{l}\text { is the cost of energy for load type } i \text { at time interval } \\
\text { number } j \text {. }\end{array}$ \\
\hline $\operatorname{Pnew}_{(i, j)}$ & $\begin{array}{l}\text { is the demand of load type } i \text { at time interval } j \text { after } \\
\text { applying load shifting technique }\end{array}$ \\
\hline $\operatorname{Pold}_{(i, j)}$ & $\begin{array}{l}\text { is the demand of load type } \mathrm{i} \text { at time interval } \mathrm{j} \text { before } \\
\text { applying load shifting technique }\end{array}$ \\
\hline$P_{(v a l)}$ & $\begin{array}{l}\text { is an extremely limiting value given by the planner for } \\
\text { load demand after applying the DSM program. }\end{array}$ \\
\hline $\boldsymbol{W h} \boldsymbol{h}_{(j)}$ & is the working hours of the factory during the day \\
\hline$N W$ & is the number of workers in this factory \\
\hline$C W_{(i, j)}$ & $\begin{array}{l}\text { is the cost of workers for load type } \mathrm{i} \text { at time interval } \\
\text { number } \mathrm{j} \text {. }\end{array}$ \\
\hline$C D$ & is the cost of peak demand \\
\hline
\end{tabular}




\begin{tabular}{|c|c|}
\hline Pmin & minimum power for new load power (for lighting) \\
\hline Pmax & $\begin{array}{l}\text { maximum power for new load power (maximum in old } \\
\text { load profile) }\end{array}$ \\
\hline$v_{i}^{k}$ & is the vector of velocity \\
\hline$w$ & is the inertial weight \\
\hline$c_{1}, c_{2}$ & are the acceleration coefficients. \\
\hline$s_{i}^{k}$ & is the current solution of individual $\mathrm{i}$ at iteration $k$. \\
\hline $\begin{array}{l}\operatorname{rand}_{1} \\
\operatorname{rand}_{2}\end{array}$ & are random numbers in the range of $[0,1]$. \\
\hline pbest & is the local best position \\
\hline $\begin{array}{c}w_{\min } \\
w_{\max }\end{array}$ & $\begin{array}{l}\text { are the minimum and maximum inertia parameter } \\
\text { weights }\end{array}$ \\
\hline Iter $_{\max }$ & is the value of maximum iterations \\
\hline Iter & value of current iteration. \\
\hline
\end{tabular}

\section{REFERENCES}

[1] Nawaz et al., "Demand-side Management of Residential Service Area Under Price-based Demand Response Program in Smart Grid," 2020 International Conference on Electrical, Communication, and Computer Engineering (ICECCE), Istanbul, Turkey, 2020, pp. 1-6.

[2] X. Zhao et al., "A model of Demand Response scheduling for cement plant," 2014 IEEE International Conference on Systems, Man, and Cybernetics (SMC), San Diego, CA, 2014, pp. 3042-3047

[3] Helin, Kristo \& Käki, Anssi \& Zakeri, Behnam \& Lahdelma, Risto \& Syri, Sanna, 2017. "Economic potential of industrial demand side management in pulp and paper industry," Energy, Elsevier, vol. 141(C), pp. 1681-1694.

[4] Kumar, S.S., \& Naik, G. "Load Shifting Technique on 24Hour Basis for a Smart-Grid to Reduce Cost and Peak Demand Using Particle Swarm Optimization", International Research Journal of Engineering and Technology, (2017), 4(10), pp. 1180-1185.

[5] M. Attia, K. H. Youssef and N. H. Abbasy, "A Comparative Analysis and Simulation of Load Shaping Techniques," 2018 IEEE PES/IAS PowerAfrica, Cape Town, 2018, pp. 664-669.

[6] M. Attia, K. H. Youssef and N. H. Abbasy, "Load Management Using Multiple Sequential Load Shaping Techniques," 2018 IEEE PES/IAS PowerAfrica, Cape Town, 2018, pp. 670-674.

[7] M. Osama, A. K. Elshenawy and M. Elsingab, "Load Management Optimization to Reduce the Demand Side Energy Cost," 2018 IEEE PES/IAS PowerAfrica, Cape Town, 2018, pp. 25-31.
[8] Davito, B., Tai, H., \& Uhlaner, R. (2010). The smart grid and the promise of demand-side management. McKinsey on Smart Grid, 3, pp. 8-44.

[9] S. K. Nayak, N. C. Sahoo and G. Panda, "Demand side management of residential loads in a smart grid using 2D particle swarm optimization technique," 2015 IEEE Power, Communication and Information Technology Conference (PCITC), Bhubaneswar, 2015, pp. 201-206.

[10] Salami, A., \& Farsi, M.M. (2015). Demand side management using direct load control for residential and industrial areas. 2015 International Congress on Electric Industry Automation (ICEIA 2015), pp.11-16.

[11] R. Vatambeti and P. K. Dhal, "A Novel Approach of Congestion Management based IEEE 30 bus using Particle Swarm Optimization Technique," 2020 International Conference on Computer Communication and Informatics (ICCCI), Coimbatore, India, 2020, pp. 1-5.

[12] Grant, M.C., \& Boyd, S.P. (2018). The CVX Users' Guide: Release 2.1. Available from: http://cvxr.com/cvx/doc/CVX.pdf. [Accessed in: Aug, 2019].

[13] Arasomwan, M.A., \& Adewumi, A.O. (2014). Improved particle swarm optimization with a collective local unimodal search for continuous optimization problems. TheScientificWorldJournal, 2014, pp.1-24.

[14] Y. Ren and S. Liu, "Modified Particle Swarm Optimization Algorithm for Engineering Structural Optimization Problem," 2017 13th International Conference on Computational Intelligence and Security (CIS), Hong Kong, 2017, pp. 504-507.

[15] The cost of electricty based on Egyption electricity company plan 2019. Available from: http://egyptera.org/ar/t3reefa.aspx [Accessed in: Dec, 2019].

Title Arabic:

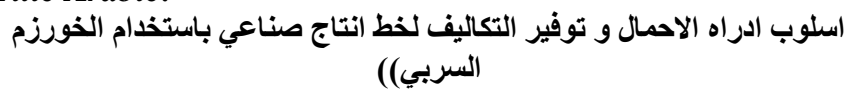

Arabic Abstract:

تحتاج الثورة الصناعية في مصر والدول النامية الأخرى إلى قدر هائل من الطاقة الطاقة

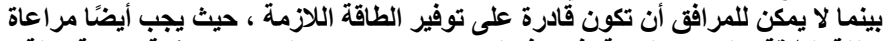

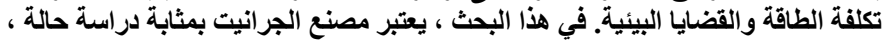

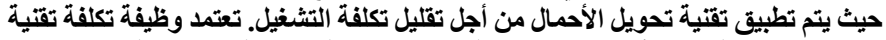

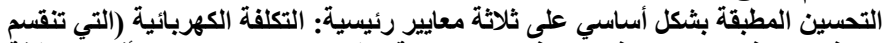

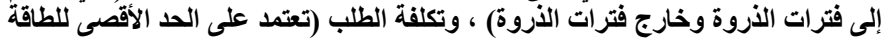

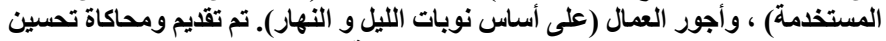

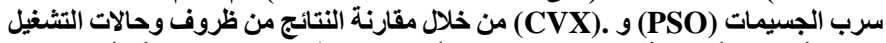

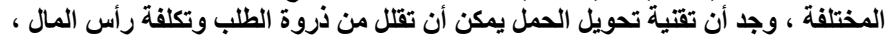

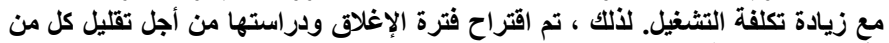
رأس المال وتكلفة التشغيل. 